\title{
Characterization of ions at Alpine waterfalls
}

\author{
P. Kolarž ${ }^{1, *}$, M. Gaisberger ${ }^{2, *}$, P. Madl ${ }^{3}$, W. Hofmann ${ }^{3}$, M. Ritter ${ }^{2}$, and A. Hartl ${ }^{2}$ \\ ${ }^{1}$ Institute of Physics, University of Belgrade, Pregrevica 118, 11080 Belgrade, Serbia \\ ${ }^{2}$ Institute of Physiology and Pathophysiology, Paracelsus Medical University, Strubergasse 21, 5020 Salzburg, Austria \\ ${ }^{3}$ Department of Materials Research and Physics, Division of Physics and Biophysics, University of Salzburg, Hellbrunner Str. \\ 34, 5020 Salzburg, Austria \\ *These authors contributed equally to this work
}

Correspondence to: P. Kolarž et al. (kolarz@ipb.ac.rs)

Received: 16 June 2011 - Published in Atmos. Chem. Phys. Discuss.: 9 September 2011

Revised: 28 March 2012 - Accepted: 9 April 2012 - Published: 24 April 2012

\begin{abstract}
During a three-year field campaign of measuring waterfall generated ions, we monitored five different waterfalls in the Austrian Alps. Most measurements were performed at the Krimml waterfall (Salzburg, Austria), which is the biggest waterfall in Europe, and the Gartl waterfall (Mölltal, Austria). We characterized spatial, time and size distributions of waterfall-generated ions under the influence of surrounding topography. The smallest ions with boundary diameters of $0.9,1.5$ and $2 \mathrm{~nm}$, were measured with a cylindrical air ion detector (CDI-06), while ion sizes from 5.5 to $350 \mathrm{~nm}$ were measured using a modified Grimm SMPS aerosol spectrometer. High negative ion concentration gradients are detected in the vicinity of the waterfalls, whereas the increase of positive ions was only moderate. Ions in the nano range were the most abundant at $2 \mathrm{~nm}$, and at $120 \mathrm{~nm}$ in the sub-micrometer range.
\end{abstract}

\section{Introduction}

\subsection{Air ions in the environment}

The term "air ions" refers to all charged airborne particles with electrical mobility. In general, they are continually created by natural sources such as cosmic rays, radioactive decay of noble gases (such as radon) in the air, and radioactive minerals of the ground. Primary ions evolve after ionization, which typically occurs within microseconds via a process of hydration and ion cluster formation into complexes, known as small air ions (charged nano-aerosols) with a typical lifetime of 5-60 s (Hõrrak et al., 2000). The central ion of a cluster can also contain one inorganic molecule and can be surrounded by one layer of water molecules. In highly pure waters, such inoculation cores are largely absent in the aerosols, at is the case in the waterfalls investigated in this study.

The near-ground ionization rate, caused by background ionization, of 10 ion pairs $\mathrm{cm}^{-3} \mathrm{~s}^{-1}$ is considered as a standard in continental areas (Chalmers, 1967). The small air ion concentration $\left(n^{ \pm}\right)$itself is determined by the following balance equation:

$\frac{d n^{ \pm}}{d t}=q-\alpha n^{ \pm} n^{\mp}-n^{ \pm} \beta Z$

where $q$ is the volumetric production rate, $Z$ is the aerosol number concentration, $\alpha$ coefficient accounts for the losses of ion-to-ion recombination and $\beta$ represents an effective ion-aerosol attachment coefficient, which is the integral over the size distribution of aerosol particles (Laakso et al., 2004; Hõrrak et al., 2008). The atmospheric electric electrode effect in near ground layer induces an imbalance between positive and negative small air ion concentrations, and results in a ratio of $n^{+} / n^{-}=1.12$ (Hoppel et al., 1986; Hõrak, 2001).

According to the size categorization provided by Hõrrak et al. (2000) and Hõrrak (2001), which uses electrical mobility to mass diameter conversion provided by Tammet (1995), air ions are classified in: small cluster ions $0.36-0.85 \mathrm{~nm}\left(3.14-1.28 \mathrm{~cm}^{2} \mathrm{~V}^{-1} \mathrm{~s}^{-1}\right)$, big cluster ions $0.85-1.6 \mathrm{~nm}\left(1.280 .5 \mathrm{~cm}^{2} \mathrm{~V}^{-1} \mathrm{~s}^{-1}\right)$, intermediate 1.6$7.4 \mathrm{~nm}\left(0.034-0.5 \mathrm{~cm}^{2} \mathrm{~V}^{-1} \mathrm{~s}^{-1}\right)$ and large ions $7.4-79 \mathrm{~nm}$ $\left(0.034-0.00041 \mathrm{~cm}^{2} \mathrm{~V}^{-1} \mathrm{~s}^{-1}\right)$. Intermediate and large ions are also called aerosol ions (Hõrrak et al., 1994). Cluster air 
ions are supposed to carry only a single elementary charge that relates mobility with mass, if the carrier gas is known (Aplin, 2008). The effect of multiple charges is assumed to occur in low concentrations in the case of large particles $>50 \mathrm{~nm}$ (Hõrrak, 2001), which is in this study considered as an artifact.

Air ion generation is caused by several, both natural and artificial mechanisms. In this study, we investigated the "waterfall effect", which creates mostly negative ions, also known as Lenard's ions (Lenard, 1892) or ballo-electric ions. Investigations of the ballo-electric ion phenomenon was started by Philipp Lenard (Lenard, 1915, 1892) and continued by Chapman (1938a, b), Blanchard (1955), Gathman and Hoppel (1970), Levin (1971), Reiter (1994), Hõrrak et al. (2006), Hirsikko et al. (2007, 2011), Laakso et al. (2006, 2007), Luts et al. (2009), Tammet et al. (2009) and others. Laakso et al. (2006) and Luts et al. (2009) proposed and analyzed several pathways which can produce waterfall ions. They found that combination of factors, such as autoionization of water molecules, fluctuating charge rearrangement, surface protrusions, evaporation of droplets formed in collisions, and Coulomb explosion serve both as the main source of intermediate ions as well as the extra source for large ions. Furthermore, they computed velocities of primary waterfall droplets required to break up into two new ones, and their velocities and dimensions.

Upon creation, waterfall droplets undergo charge redistribution forming dipoles with negatively charged surfaces. The phenomenon of charge separation occurs as a consequence of the disruption of the water surface by splashing and bubbling, when moving liquid is aerosolized at an obstacle, aqueous surface or by aerodynamic break-up of water droplets during free fall (see Fig. 1). After breaking up, smaller fragments (or clusters) carry negatively charged $\mathrm{OH}^{-}$ions, while the remaining bigger fragments become positive, according to:

$$
\left(\mathrm{H}_{2} \mathrm{O}\right)_{n} \rightarrow\left(\mathrm{H}_{3} \mathrm{O}^{+}\right)\left(\mathrm{H}_{2} \mathrm{O}\right)_{n-m}+\mathrm{OH}^{-}\left(\mathrm{H}_{2} \mathrm{O}\right)_{m-2}
$$

where $\mathrm{m} \gg \mathrm{n}$, where large proton clusters are known as $\mathrm{H}_{3} \mathrm{O}^{+}\left(\mathrm{H}_{2} \mathrm{O}\right)_{20}$ (Hulthe et al., 1997; Laakso et al., 2006; Vostrikov et al., 2006; Parts et al., 2007; Luts et al., 2009). A positive value of droplet surface potential $(+0.1 \mathrm{~V})$ indicates that the water dipoles are preferentially oriented with the negative pole toward the gas phase, while the positive pole is oriented towards the liquid phase (Parfenyuk, 2002). Botti et al. (2004) suggested that $\mathrm{OH}^{-}$ions are hydrated with $4 \mathrm{H}_{2} \mathrm{O}$ molecules with a presence of a weakly bound fifth water molecule, close to the hydrogen atoms. Negatively charged particles remain in the air and become thermophoretically dispersed, due to the cold air stream caused by the temperature difference between water and the surrounding air. The larger positively charged droplets precipitate to the ground, i.e. in the pond. As a result, negative air ion concentrations near waterfalls can reach several tens of thousands per cubic centimeter. Laakso et al. (2007) found that the diame-

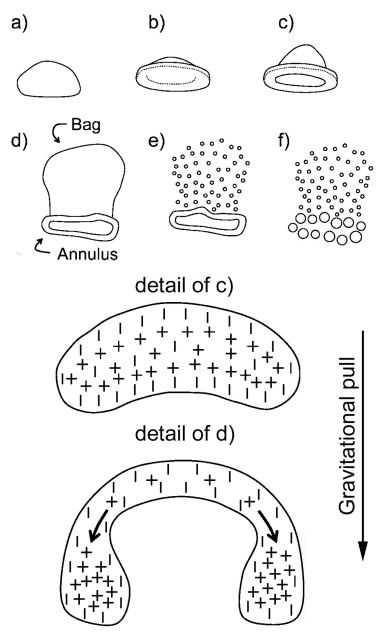

Fig. 1. Theoretical concept of the charge separation mechanism of a falling water droplet. Water bag formation (a-d), fracture into micro-bubbles (e-f) (modified according to Zilch et al., 2008).

ter of waterfall-related negative air ions range between 1.5$10 \mathrm{~nm}$, whereby $2 \mathrm{~nm}$ sized negative ions were most abundant. Tammet et al. (2009) investigated the generation and mobility distribution of ballo-electric ions during rain, finding that the mobilities of most of these ions were between 0.1 and $0.5 \mathrm{~cm}^{2} \mathrm{~V}^{-1} \mathrm{~s}^{-1}(1.6-4.0 \mathrm{~nm})$ with distribution maxima between 0.20 and $0.27 \mathrm{~cm}^{2} \mathrm{~V}^{-1} \mathrm{~s}^{-1}(2.22-2.64 \mathrm{~nm})$.

The goal of this study was to investigate the spatial, time and mobility distributions of waterfall-generated ions, and the location-specific waterfall physics and topographic structures in a region of the Austrian Alps. The physical characterization of waterfall-generated ions was part of a randomized controlled clinical study, which focused on the influence of these waterfall generated ions and aerosols on human lung function. Physiological and medical effects of ions and waterfalls has been described (Iwama, 2004; Yamada et al., 2005; Takahashi et al., 2008), but interpretation of specific health-related effects still require a thorough physical characterization. In the present study we analyzed five waterfalls with respect to their distribution of ions.

\section{Methods}

\subsection{Instrumentation and measurements}

Integral aspiration counter, also known as Gerdien condenser, is the most commonly used tool for atmospheric conductivity measurements (Gerdien, 1905). Its operation is based on the polarizing voltage that is applied between two aspirated coaxial electrodes. Ions of the same polarity as polarising voltage are deflected toward the collecting electrode 
depositing charge $\left(q=1.62 \times 10^{-19} \mathrm{C}\right)$ and generating current $(I)$ :

$I=n \cdot q \cdot Q$

where $Q$ is air-flow through the electrodes.

The limiting mobility of the aspiration condenser $\left(\mu_{c}\right)$, is defined as a combination of polarizing voltage $(U)$ and air flow:

$\mu_{c}=\frac{V_{S} \cdot\left(R_{2}^{2}-R_{1}^{2}\right) \cdot \ln \left(R_{2} / R_{1}\right)}{2 \cdot L \cdot U}$

where $R_{2}$ and $R_{1}$ are the radii of the polarizing and collecting electrode; $L$ is the collecting electrode length and $V_{S}$ is the air velocity through the electrodes (Applin, 2005). Gerdien integral ion counters collect all ions with the mobilities above those defined by polarizing voltage and flow rate $\left(\mu_{c}\right)$ of the instrument, but also they collect a small fraction of excessive ions with lower mobilities. Mobility distribution of integral counters is commonly obtained using second derivation of the current to voltage $(I-U)$ characteristic curve (Tammet, 1970; Horrak et al., 2008; Flagan, 1998).

Concentrations of small and intermediate ions with mobilities below $0.3 \mathrm{~cm}^{2} \mathrm{~V}^{-1} \mathrm{~s}^{-1}$ were measured using three identical Gerdien condenser detectors (CDI-06), constructed at the Institute of Physics, Belgrade. Using the dynamic property of ionic motion in an electric field, the polarizing voltage and air flow on three identical CDI-06 detectors was set to measure ions with the following limiting mobilities: $1.18,0.55$ and $0.3 \mathrm{~cm}^{2} \mathrm{~V}^{-1} \mathrm{~s}^{-1}$, which corresponds to the boundary mass diameters of $0.9,1.5$ and $2 \mathrm{~nm}$ (Eq. 3). Ion mobility (measured by CDI-06) to mass diameter conversion was based on the formulation given by Tammet (1995). Selected limiting mobilities correspond to characteristic ionsizes originating from waterfalls (WF), which is around $2 \mathrm{~nm}$ (Laakso et al., 2007), and by background ionization sources, i.e. nuclear decay as well as cosmic rays - with the latter up to $0.9 \mathrm{~nm}$ (small cluster ions).

The relatively large electrode cross-section $\left(R_{1}=0.028 \mathrm{~m}, R_{2}=0.005 \mathrm{~m}\right)$ along with the collecting electrode length $(L=0.4 \mathrm{~m})$ provides a high air flow $\left(0.0048 \mathrm{~m}^{3} \mathrm{~s}^{-1}\right)$ and intense signal to use a small measuring resistor $\left(R_{M}=1 \mathrm{G} \Omega\right)$, thus resulting in a reduced measuring uncertainty. The collecting electrode is at virtual ground potential; with the measuring system, including the polarization circuit, galvanically separated from the power supply and the PC communications port (USB). Each of the three detectors has its own power supply, temperature, pressure and relative humidity sensor, and also sophisticated features such as zeroing (eliminates zero offset drifts during measurements), live data acquisition, with programmable data averaging, sampling and automatic polarity change options (Kolarž et al., 2012).
According to Eq. (2), the detector amplifier (i.e. A/D converter) output signal to air ion concentration conversion factor was calibrated prior to each measurement using a Keithley Picoampere 261 source. The limiting ion mobility was calculated using Eq. (3). The instrumental uncertainties under regular operational conditions are about $5 \%$ (Kolarž et al., 2009). Taking into account the extreme and difficult conditions during the field campaign, and particularly in the close vicinity to the WFs, an additional uncertainty should be added. Yet, efforts, such as correction due to repulsion of small ions at the inlet of the detector (Anderson et al., 1991; Misaki, 1961), maintaining constant number of revolutions per minute of the fans, thermostating both the electronics and electrodes, usage of additional protective case and manual zeroing procedure have been employed to limit additional uncertainties to around $10 \%$. Uncertainty due to the collection of excessive ions with lower mobilities than limiting was estimated up to $5 \%$. Altogether, by using the "root-sum-ofsquares" method combined standard uncertainty amounts to $12 \%$.

Ion concentrations in the size ranges of $0.36-0.9 \mathrm{~nm}, 0.9-$ $1.5 \mathrm{~nm}$ and $1.5-2 \mathrm{~nm}$ were found from the data of three ion detectors (CDI-06), set to measure ions at the corresponding boundary diameters of $0.9,1.5$ and $2 \mathrm{~nm}$, using a simple subtraction method (Figs. 9, 13). Obtaining size distribution using second derivation of I-U characteristic was not possible using this setup, thereby increasing measuring uncertainty. Although the determination of ion mobilities using integral Gerdien counters is not as accurate and narrowband as for e.g. a DMA (differential mobility analyzer), portability and robustness compensate for that disadvantage and allow measurement on nearly impassable terrains.

Further away from the WF, in conditions where mostly small cluster ions prevail (except in cases of nucleation bursts of intermediate ions), two detectors which are measuring ions with lower mobilities should detect equal or slightly higher ion concentrations compared to one detector measuring small ions (Laakso et al., 2007). As stated above, similar applies to the ratio of positive and negative background ion concentrations on the reference sites, where $n^{+} / n^{-}$should be about 1.12 .

To test the performance of the instrumentation, an intercomparison between the cylindrical ion detectors was performed (Fig. 2). Two detectors, with the same voltage and amplification settings, placed side by side, were used to measure negative ion concentration gradients near the Krimml WF. Comparison of detectors reveals the Pearson correlation coefficient of $r=0.97$, which is more than satisfactory considering the sampling conditions encountered during the field campaign. Testing was conducted also at different sites and locations, and under different detector setups. The time resolution of CDI-06 detectors was set on $2 \mathrm{~s}$ for all measurements so that sufficient statistics and data analysis could be achieved. 


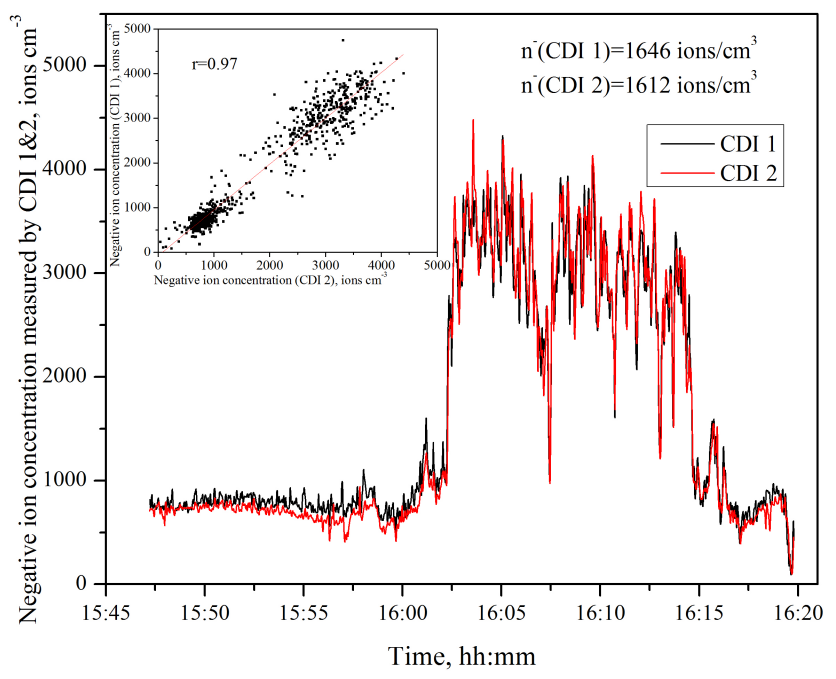

Fig. 2. Intercomparison of ion detectors (CDI-06) nearby Krimml WF versus time. Correlation coefficient 0.97 .

Air ion particles in the size range from 5.5 to $358 \mathrm{~nm}$ were measured with the Grimm SMPS (Scanning Mobility Particle Sizer). It consists of a CPC (Condensation Particle Counter, model 5403) to quantify the particle concentration, and is attached to a middle sized M-DMA (MediumDifferential Mobility Analyzer) column (5540 26 Reischl Vienna type) for size class differentiation. Within the DMA, the particles are selected according to their electrical mobility, which is accomplished using a ${ }^{241} \mathrm{Am}$ radioactive source mounted on the DMA air inlet. To avoid neutralization of the aerosolized ions, this so-called "neutralizer" was detached from the M-DMA resulting in an SMPS detector which is able to count negatively charged particles. SMPS default conversion algorithm is using Stokes Millikan mobility diameter (Hirsikko et al., 2011). Instrumental losses are also accounted by the built-in algorithm and take into account the time response characteristic of the CPC in terms of flow and voltage stepping, the aerosol residence time within the DMA, and particle losses as particles pass through the DMA as well as the CPC (Heim et al., 2004). Although the SMPS efficiency correction acts over the full spectrum, the smaller particle spectrum below $10 \mathrm{~nm}$ is more affected than the scan window above this threshold. Similarly, its impact on the DMA-correction is larger than on the CPC-correction. Altogether, the correction algorithm affects the overall particle count per scan by roughly $30 \%$ for the DMA and approximately $10 \%$ for the CPC. The entire system was operated with a backup battery-operated power supply, enabling at least 8 hours of uninterrupted operation in the field.

Due to the dynamics of waterfall generated aerosols, monitoring the inventory with a SMPS is not the first choice, as it requires a $240 \mathrm{~s}$ interval for the completion of a full scan. Therefore, the SMPS was operated in fast mode, which uses only 22 voltage channels, instead of the 44 voltage channels in the normal operational mode. In this mode, each information from the counts detected in-between the voltage step are utilized to calculate an additional series of 22 pseudovoltage channels. Together, these combine again in the total number of 44 channels (Heim et al., 2004). The ideal detector should at least measure in second intervals, like the ELPI. However, this instrument, due to its weight and power requirements, is not well suited for field measurements. This shortage was overcome by making at least three full SMPS scans at every point, each divided into 44 size channels, and each channel computed as an average of 9 individual recordings (out of which the 1st and 9th are omitted as the system dynamically changes the voltage when switching from one size bin to the next). Due to the nature of its detection principle, the SMPS only enables to measure negatively charged particles thus depriving us from monitoring positively charged aerosols in the $200 \mathrm{~nm}$ size range and beyond, as reported by Reiter (1994).

Atmospheric data, such as temperature and wind speed, were measured by a PCE-007 anemometer attached to a data logger (PCE Deutschland GmbH, Germany, http://www. pce-instruments.com). Radon concentration in the air was measured with a continuous radon gas monitor RAD7 (Durridge Co, USA, http://www.durridge.com). Natural radioactivity in the air was detected using a Gamma Scout counter based on Geiger-Müller principle (Gamma-Scout GmbH \& Co. KG, Germany, http://www.gamma-scout.com).

Measuring of ion concentrations in the vicinity of the WFs is difficult and affected by water aerosols. Beyond contributing to the increase in relative humidity, these droplets wet the instruments, soak the electrodes of the CDI and thus cause current leakages in the electrode system, and amplifying electronics. In addition, the temperature gradient at the waterfalls results in a heavy surge, which is directed downstream away from the WF in periodical gust. These gusts are carrying water aerosols, and can be highly loaded with air ions. Periods of intense gusts are followed by modest ones and typically last between 5 and 40 seconds, a phenomenon which is intensified at the Krimml waterfall where three falling cascades generate very complex air-flow patterns.

We partly overcome these impairments of the measurement conditions by encasing the CDI instruments in aluminium boxes with inlets for the probes and outlet for exhaust. The SMPS was also operated in a sealed housing, thus only subjecting the inlet to excessive humidity. All instruments were mounted onto a 4-wheel trolley (Fig. 3).

\section{Measurements and discussion}

The present study lasted from 2008 until 2010. At the very beginning, measurements on several different waterfalls were conducted (shown in Sect. 3.1). Early preliminary data indicated significant health effects of the Krimml waterfall, therefore, time and spatial measurements (Sect. 3.2), and 
Table 1. Height of WF cascades (approximate), average and maximal water flow. Bold numbers represent the heights of the investigated cascades.

\begin{tabular}{llll}
\hline WF name & Height $(\mathrm{m})$ & $\begin{array}{l}\text { Average water } \\
\text { flow }\left(\mathrm{m}^{3} \mathrm{~s}^{-1}\right)\end{array}$ & $\begin{array}{l}\text { Maximal water } \\
\text { flow }\left(\mathrm{m}^{3} \mathrm{~s}^{-1}\right)\end{array}$ \\
\hline Krimml & $140 \times 100 \times \mathbf{1 4 0}$ & 5.1 & 17.5 \\
Stuiben & $150 \times \mathbf{1 5 0}$ & 1.6 & 2 \\
Bad Gastein & $310($ measured cascade 50) & 1.83 & 6.8 \\
Gartl & $100(50 \times \mathbf{5 0})$ & 0.6 & 0.9 \\
Artificial (river Möll) & $\mathbf{5}$ & 1.33 & 4.66 \\
\hline
\end{tabular}

Table 2. Overview of the ion $(\leq 2 \mathrm{~nm})$ concentrations measured at closest range of the WFs and at control places (CP) during July 2008.

\begin{tabular}{lccccccc}
\hline WF name & $\begin{array}{c}\text { Average WF ion concentrations } \\
\text { (ions m }\end{array}$ & $\begin{array}{c}\text { Max.WF ion concentrations } \\
\text { (ions m }\end{array}$ & $\begin{array}{c}\text { Average ion concentrations } \\
\text { at ref. site, (ions m }\end{array}$ & $\begin{array}{c}\text { Conc. increase } \\
n_{\mathrm{WF}}^{-3} / n_{\mathrm{CP}}^{-}\end{array}$ & $\begin{array}{c}\text { Conc. increase } \\
n_{\mathrm{WF}}^{+} / n_{\mathrm{CP}}^{+}\end{array}$ \\
\hline & negative & positive & negative & positive & negative & positive & \\
Krimml & 16581 & 1040 & 27540 & 1736 & 460 & 476 & 36 \\
Stuiben & 43913 & 2142 & 54359 & 3098 & 546 & 620 & 80 \\
Bad Gastein & 24748 & 1290 & 31606 & 428 & 774 & 510 & 32 \\
Gartl & 42660 & 1798 & 57510 & 2400 & 840 & 760 & 31 \\
Artificial (river Möll) & 3294 & 1446 & 6251 & 1582 & 306 & 544 & 2 \\
\hline
\end{tabular}

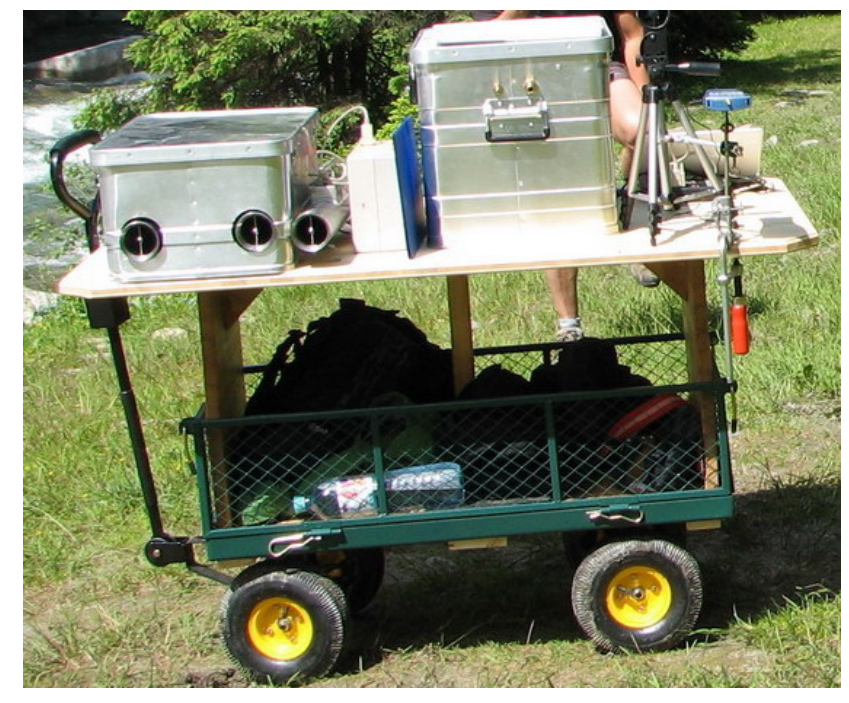

Fig. 3. Air ion detectors (left), SMPS, anemometer and GPS (middle) and field strength meter (right).

characterization of ion size distribution (Sect. 3.3) were performed.

\subsection{Characterization of 5 different Alpine waterfalls}

During July 2008, five WFs were investigated, and compared with control sites lacking WF-related ions. In the topography of the Austrian Alps numerous glaciers are embedded feeding their liquid phase into creeks. These collecting mountain torrents form little cascades which also generate WF ions

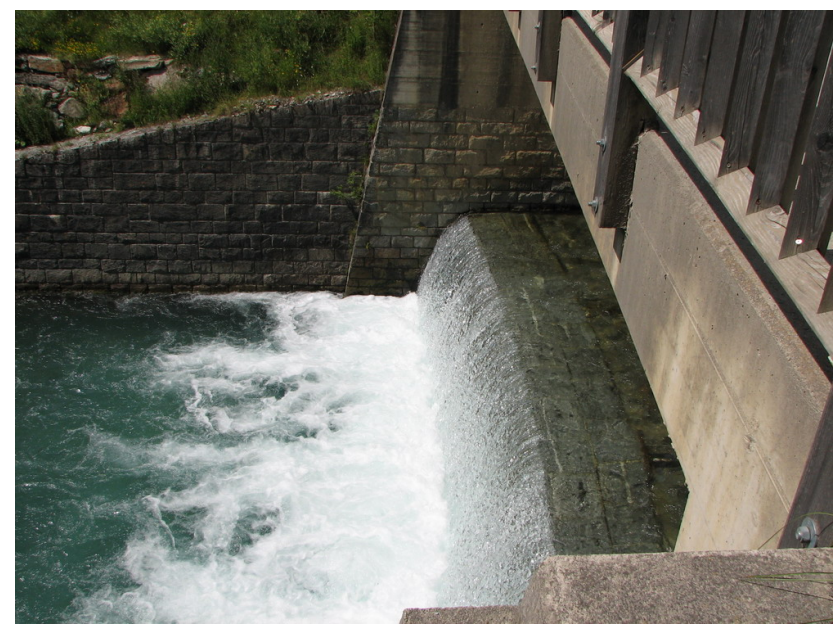

Fig. 4. Artificial WF at the river Möll.

thus leading to variable ion distribution spectra in their embedded areas.

Measurements at the WFs have been carried out during midday, along existing footpaths, using a CDI-06 setting that has been configured to measure ions with mobilities up to $1.18 \mathrm{~cm}^{2} \mathrm{~V}^{-1} \mathrm{~s}^{-1}$ ( $2 \mathrm{~nm}$ in diameter).

Table 1 lists the height, average and maximal water flow of each WF. Positive and negative air ion averages, and maximal number concentrations of ions are given in Table 2. At all sites ion concentrations were measured at places of maximal ionization and allowable wetting of the instruments. Compared to the control sites, the highest increase of the concentration of negative ions (up to $2 \mathrm{~nm}$ ) was found to be 80 -fold 
(Stuiben waterfall). Ion concentrations fluctuate depending on the amount of water flowing, which is subject to seasonal variations and oscillates with the melting of the glaciers. In contrast, the origin and structure of the ions generated at reference sites arise mostly from natural radioactivity, which is subject to diurnal changes and related to the fluctuation in concentrations of radon, thorium and their progenies (Kolarž et al., 2009; Chandrashekara, et al., 2006). Accordingly, the presented relations between alpine WFs and background air ion concentration vary diurnally and seasonally.

The data in Tables 1 and 2, lead to the conclusion that the production of WF ions not only depends on the height of the WF and its quantity of water flowing per unit of time, but also on the location and shape of the WF, the surrounding topography, and of course, the location of the measuring points.

Figure 4 shows the artificial WF on the river Möll with a cascade of $5 \mathrm{~m}$ height. This artificial WF differs from the other WFs, in that the water pours straight past a manmade barrier into the bottom pond, no water splashing on rocks takes place. Although ion concentrations are 11-fold higher than background measurements, they are much lower compared to the other investigated WFs (Table 2). Possible mechanisms contributing to WF-related ion generation could be bubble break-up on aqueous surfaces, and rapid decline in relative humidity as the aerosolised droplets drift further off the WF (Laakso et al., 2006). This implies that if the particle size is larger than the Kelvin diameter, the aerosol particles will grow, if the particle size is smaller, they will evaporate. Hence, as one moves away from the waterfall and due to the change in super-saturated conditions, the corresponding Kelvin droplet diameter becomes larger as under-saturated conditions are reached (decrease in relative humidity and increase in temperature), which causes the WF-generated aerosols to shrink in size. Furthermore, charge separation via aerodynamic break-up of micrometersized water droplets into nano-sized aerosols may play a role (Fig. 1; Zilch et al., 2008). Nevertheless, water droplets hitting a surface (rock, water) represents the most prominent mechanism of ion formation by bubble bursting, thus yielding nano-sized aerosols.

\subsection{Ion measurements at the Krimml waterfall}

The Krimml waterfall is located in the northern region of the "Hohe Tauern" - a part of the eastern Alpine region. It belongs to a glacial creek named "Krimmler Ache" whose water flows according to the season. In July the average throughput is about $5.5 \mathrm{~m}^{3} \mathrm{~s}^{-1}$, whereas it is only $0.14 \mathrm{~m}^{3} \mathrm{~s}^{-1}$ in February. The WF itself consists of three consecutive cascades, with heights of $140 \mathrm{~m}, 100 \mathrm{~m}$ and $140 \mathrm{~m}$ (Fig. 5). The base of the WF is at an altitude of around $1100 \mathrm{~m}$ above sea level. Like most of alpine WFs, it is surrounded with high cliffs that determine local atmospheric parameters and air motion. Chemical analysis of the water revealed a $\mathrm{pH}$ close to neutral (7.36), with very low concentra-

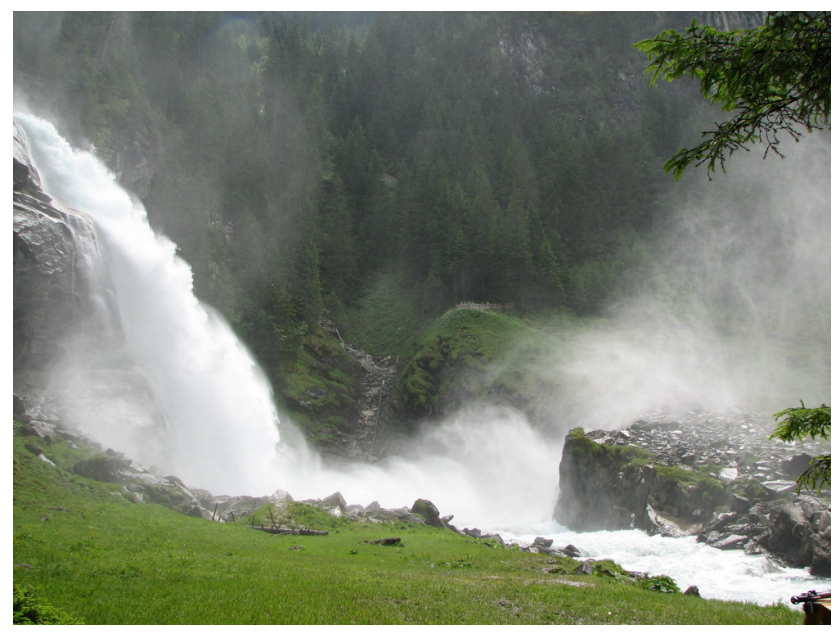

Fig. 5. The last of three cascades at the Krimml WF.

tions of $\mathrm{Ca}^{2+}\left(3.45 \mathrm{mg} \mathrm{L}^{-1}\right), \mathrm{Mg}^{2+}\left(1.22 \mathrm{mg} \mathrm{L}^{-1}\right)$ and $\mathrm{Cl}^{-}$ $\left(0.26 \mathrm{mg} \mathrm{L}^{-1}\right)$. Conductivity was $30 \mu \mathrm{S} \mathrm{cm}^{-1}$. A microbiological analysis elicited a moderate count of colony forming units $\left(\leq 100 \mathrm{CFU} \mathrm{ml}^{-1}\right)$.

During the 2009 field campaign, a series of 7-day measurements of ions $\leq 2 \mathrm{~nm}$ has been performed, including two separate field campaigns: 10-26 July as well as 9-23 September. Measurements were carried out twice a day, and consisted of a sampling session during the morning hours (around noon) and one in the afternoon (around $16 \mathrm{~h}$ ) for $1 \mathrm{~h}$ each. According to the data provided by the authorities of the local hydro power plant, which is just $700 \mathrm{~m}$ downstream from the fall, the average water flow in June was $14.4 \mathrm{~m}^{3} \mathrm{~s}^{-1}$ whereas in September it was $5.5 \mathrm{~m}^{3} \mathrm{~s}^{-1}$. The former is 2.6 times larger than the latter and directly correlating with the period of glacier melting. Daily variations of negative WF ion concentrations were within the $8 \%$ range. However, the average ion concentration in July $\left(10944\right.$ ions $\left.\mathrm{cm}^{-3}\right)$ was 1.5 times higher than in September $\left(7502\right.$ ions $\left.\mathrm{cm}^{-3}\right)$. While daily differences in ion concentrations are the consequence of local meteorological parameters, the significant difference between July and September obviously correlates with the water flow.

Average spatial distributions of ions $\leq 2 \mathrm{~nm}$ were measured during the summer seasons 2007-2010 on both sides of the WF (Fig. 6). Distances were measured from the base of the lowest cascade (using Google earth coordinates: N47.208283, E12.170859). The reference site is located $547 \mathrm{~m}$ away from the falls (see orographic right side), assuming that no WF-related ions are present there. The reason for the relatively short gradient distance on the orographic left side is due to the dense forest cover that dominates the farther site some $228 \mathrm{~m}$ from the WF. All ion measurements were carried out at points that ensure that the instruments were not subject to instant flooding. Accordingly, the nearest measuring points were $57 \mathrm{~m}$ and $75 \mathrm{~m}$ on the orographic left 


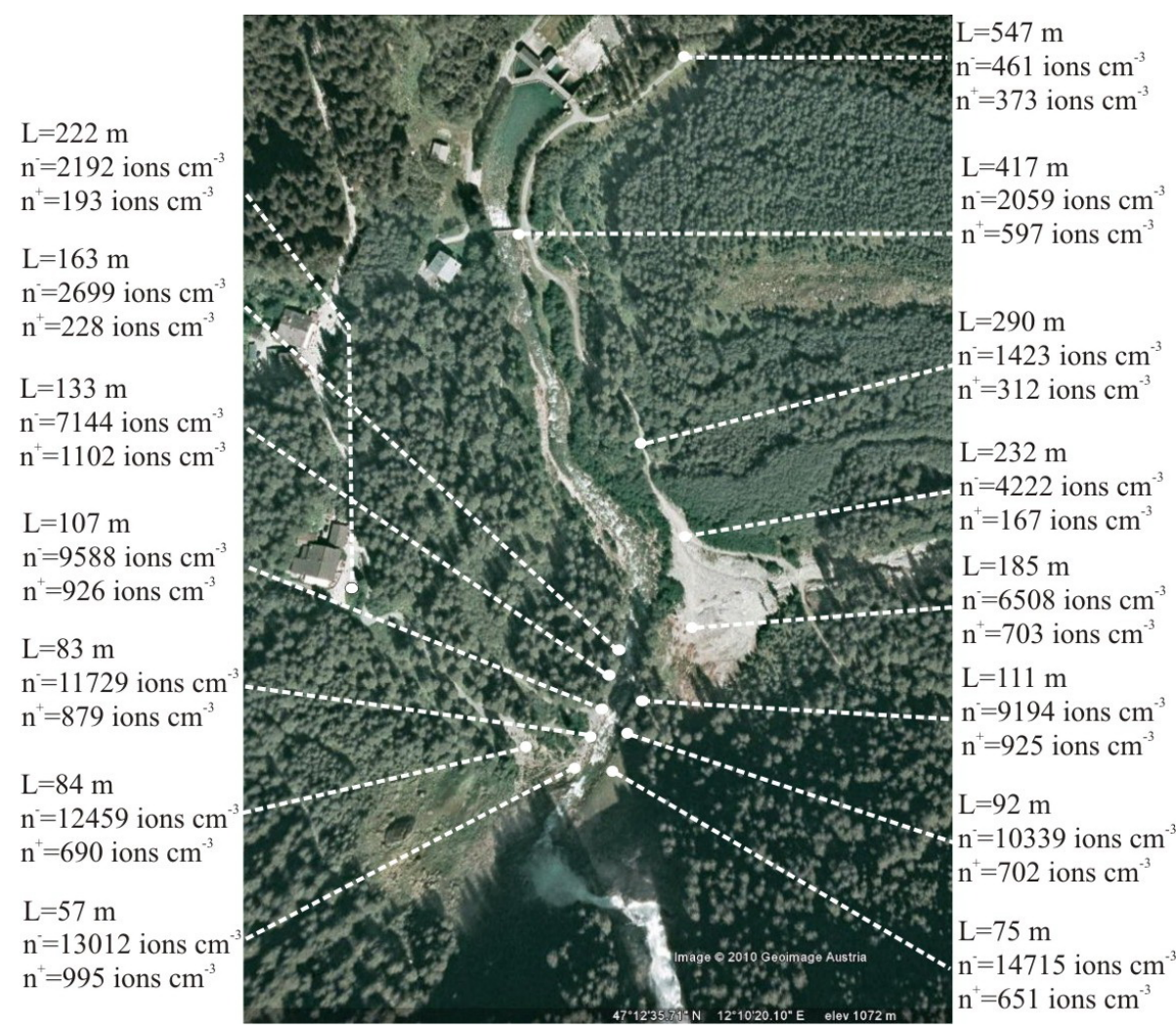

Fig. 6. Average concentrations of ions $\leq 2 \mathrm{~nm}$ measured in the summer period from 2008 to 2010. on both sides of the Krimml WF. The distances from the WF were measured via GPS and visualized on a Google Earth map.

and right side of the Krimml WF, respectively. Both measuring points are slightly shifted out of the main axis, which are directed towards the left orographic uphill side (Fig. 5 and aerial view of Fig. 6). The differences between the maximal values on the left and the right side of the WF, i.e. the creek, arise from the topographic configuration, the time variations when measurements were performed, complex turbulent airflow generated by the huge amount of water pouring into the pond and varied solar flux within the upper Krimml valley.

In comparison with the other WFs that were measured (Table 2), the maximal ion concentrations generated near the Krimml WF were apparently low, i.e. only about 20 times higher than the measured background, while maximal ion concentrations at the Gartl WF (Döllach) amounted to $6 \times 10^{4}$ ions $\mathrm{cm}^{-3}$, i.e. 120 times higher than the measured background. Noteworthy for our field observation is the following: the Krimml WF generates much more aerosols but fewer in the sub-nano-size range, and wetting of the instrumentation was much more prevalent than at the other WFs (Fig. 5). Due to nice weather conditions, the relative humidity did not exceed the critical limit ( $>80 \%$ ) for a proper function of the instrumentation.
Figure 7 shows integral values of ions with boundary size limits of $0.36-0.9 \mathrm{~nm}, 0.36-1.5 \mathrm{~nm}$ and $0.36-2 \mathrm{~nm}$ on orographic right side of the Krimml WF. As mentioned before, the non-linear decay function of the negative ion concentration is caused by the local topography and wind patterns. An obvious decrease of ion concentration with distance from the base of the WF is visible in Figs. 6 and 7, likewise there is an increase of the unipolarity coefficient at the measuring point $290 \mathrm{~m}$ from the base of the WF (Fig. 8). Both are attributable to the shift in location, i.e. moving away from the river $(58 \mathrm{~m})$ (Fig. 6). On the other hand, the measuring point $222 \mathrm{~m}$ far on the orographic left side showed significant presence of WF-generated ions although it is almost $200 \mathrm{~m}$ away from the river. This is probably due to orientation of the WF, which upon hitting the ground, bends slightly towards the orographic right, leaving part of the mainstream aerosol plume in this direction. Detection of positive ions did not reveal significant increases in concentrations, and only 0.36 $2 \mathrm{~nm}$-sized ions showed a correlation $(r=0.6)$ between positive and negative ion gradients. Interestingly, all three dimensions of positive ions were rising with distance within the first hundred meters from the WF and decreased further afield. This is probably due to very high concentrations of negative ions, as well as aerosols, in the vicinity of the WF. This indicates that higher coefficients of $\alpha$ and $\beta$ (see Eq. 1), 


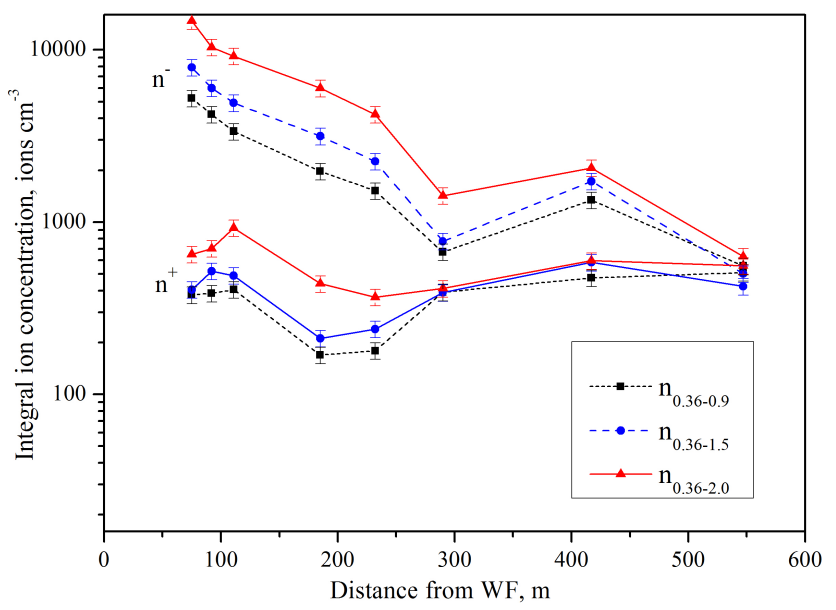

Fig. 7. Integral ion concentration distribution by ion boundary diameter and polarity versus distance, measured at the Krimml WF, orographic right side.

amplified by strong turbulent air flow patterns must be taken into consideration. The average wind speed from the first to the last point measured on the riverbanks was $4.6 \mathrm{~m} \mathrm{~s}^{-1}$. Approximate calculations revealed that under these circumstances, WF-related ions could persist up to $120 \mathrm{~s}$.

Equalization of the smallest positive and negative air ion concentrations is a signal that almost all WF-related negative ions are in some way neutralized. The remaining ones can be traced back to the formation mechanisms usually associated to natural radioactivity and cosmic radiation. Air ions created by mentioned ionizing sources are smaller than WF-related ions. Their size range is shown by the reference point data series $(547 \mathrm{~m})$ in which the ions with boundary diameter of $0.9 \mathrm{~nm}(0.36-0.9 \mathrm{~nm})$ were the most abundant that is visible in Figs. 7, 8 and 9.

Supplementary measurements of radon dissolved in water, assessed with the RAD7 instrument showed radon concentrations in the water above and below the Krimml WF to be 141 and $148 \mathrm{~Bq} \mathrm{~m}^{-3}$, respectively, hence they remain negligible for the overall ion production rate. Also, natural radioactivity in the air was measured with a Gamma Scout counter, eliciting typical background values of $\sim 0.15 \mathrm{mSv} \mathrm{h}^{-1}$.

As outlined in the "Methods" section, the ion diameter range from 0.36 to $350.4 \mathrm{~nm}$ was measured using CDI-06 and modified SMPS with M-DMA at five measuring points (Fig. 9). By operating the SMPS with and without the ${ }^{241} \mathrm{Am}$ neutralizer, it was possible to uncover the differences in the spectra. Besides the sharp increase in sub- $20 \mathrm{~nm}$ size range, when the SMPS was operated without the neutralizer, the remainder of the spectra $(20-350 \mathrm{~nm})$ still reveal similar trends, regardless of whether the neutralization source was attached or not.

According to Laakso et al. (2007), the ion-effect of the WF is visible only in ions smaller than approximately $30 \mathrm{~nm}$ with a maximal rise of negative ion concentration near the

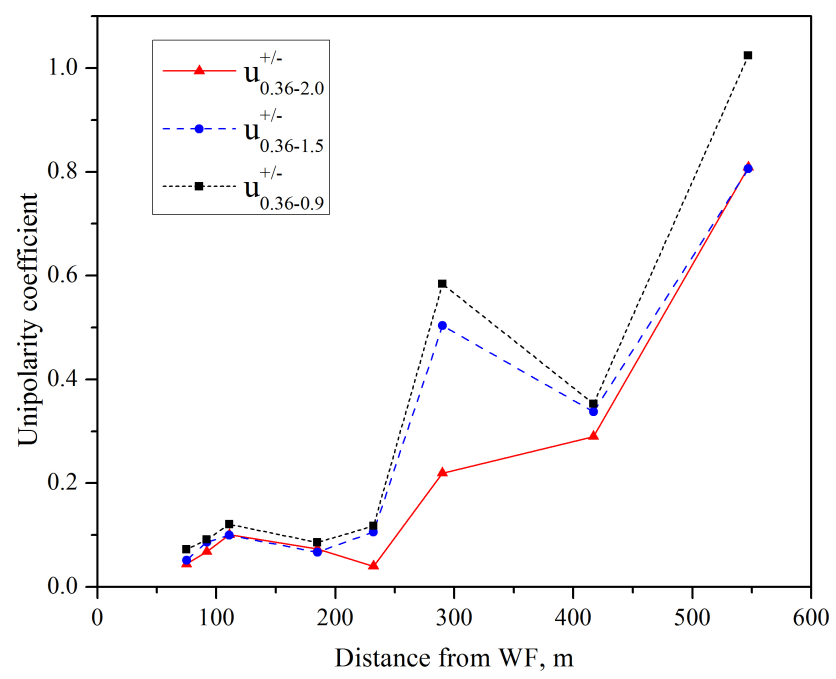

Fig. 8. Unipolarity coefficients $\left(u^{ \pm}\right)$for 3 different ion sizes versus distance measured at the Krimml WF, orographic right side.

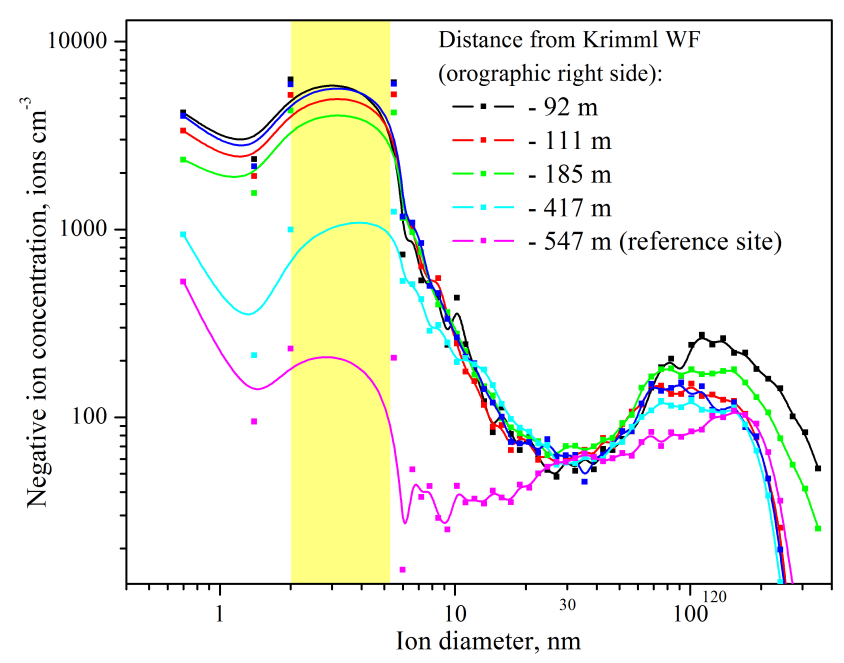

Fig. 9. Ion concentration distribution by size measured at different distances on 1 July 2010 at Krimml WF, orographic right side. Shaded area indicates interpolated values (cubic B-spline) between CDI-06 (0.36-2.0nm) and SMPS (5.5-350nm) measurements. The $547 \mathrm{~m}$ data series (magenta curve) represents the reference site where no WF-generated ions were expected to occur.

WF in the size range of 1.5 to $10 \mathrm{~nm}$, which is also in agreement with our data. In the size range of heavy large ions between 25 and $40 \mathrm{~nm}$ there was no increase in observable WF-generated ions, whereas larger ions are present from 40 to above $350 \mathrm{~nm}$, whereby clustering took place into a size of approximately $120 \mathrm{~nm}$ (their concentration directly at the WF was three-fold higher than at the reference site). Furthermore, ions with a boundary diameter up to $0.9 \mathrm{~nm}$ increased in the close vicinity of the falls, indicating the extended spectrum of the WF-related ion size range along with its mobility. 


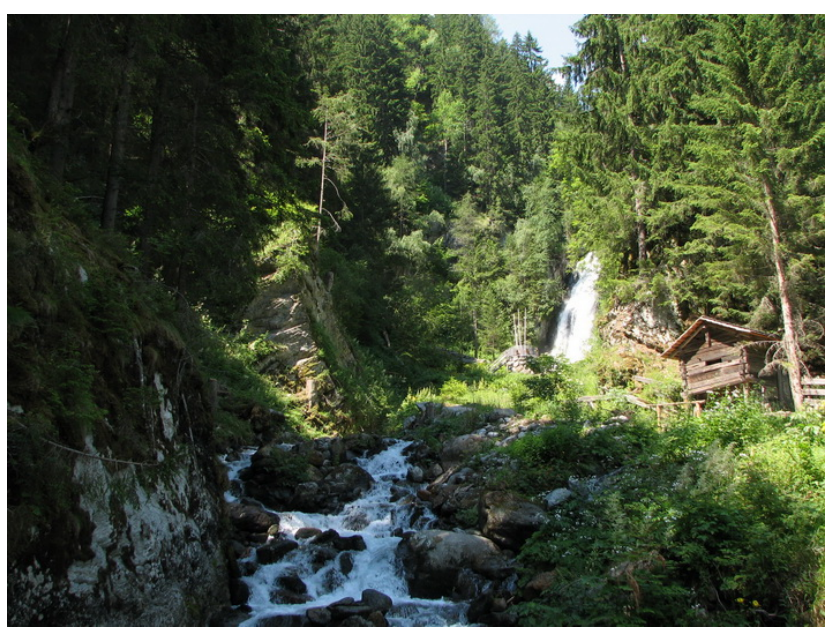

Fig. 10. Gartl WF with surroundings.

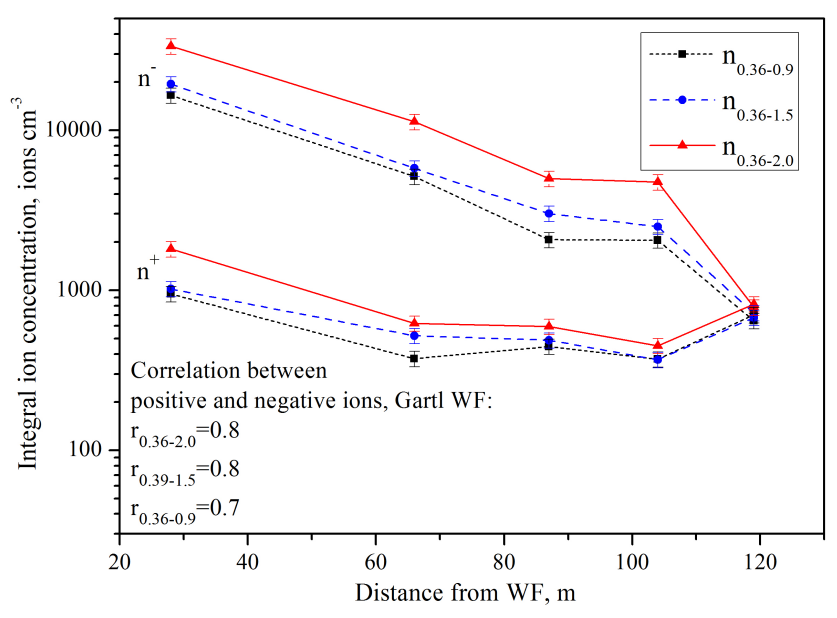

Fig. 11. Integral ion concentration distribution by ion boundary diameter and polarity versus distance measured at the Gartl WF.

\subsection{Ion measurements at the Gartl waterfall}

The Gartl WF, as shown in Fig. 10, is located in the southern sector of the "Hohe Tauern" region and is also part of the Alpine region. It is composed of 2 cascades in series. Together they are about $50 \mathrm{~m}$ high and steeply plunge into the pond at the base of the falls. This WF is tightly embedded into a narrow topographic setting, encompassing a small valley opening closely surrounded with high cliffs, which are directing the air stream downhill.

The generated ion gradients at Gartl waterfall show similar characteristics as observed at the Krimml waterfall. However, this WF produces significantly higher ion concentrations. Unlike the Krimml waterfall, the positive ion concentrations of this WF were low in the vicinity of the fall itself (Figs. 11, 12). Strong correlation coefficients between positive and negative ions $(r \sim 0.8)$ of the same size were ob-

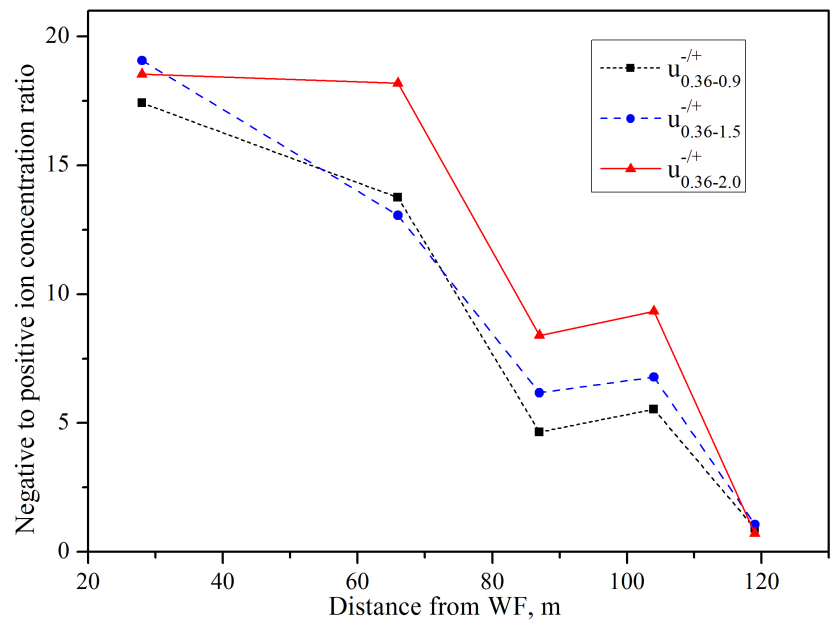

Fig. 12. Negative and positive integral ion concentration ratios $\left(u^{\mp}\right)$ versus distance at the Gartl WF.

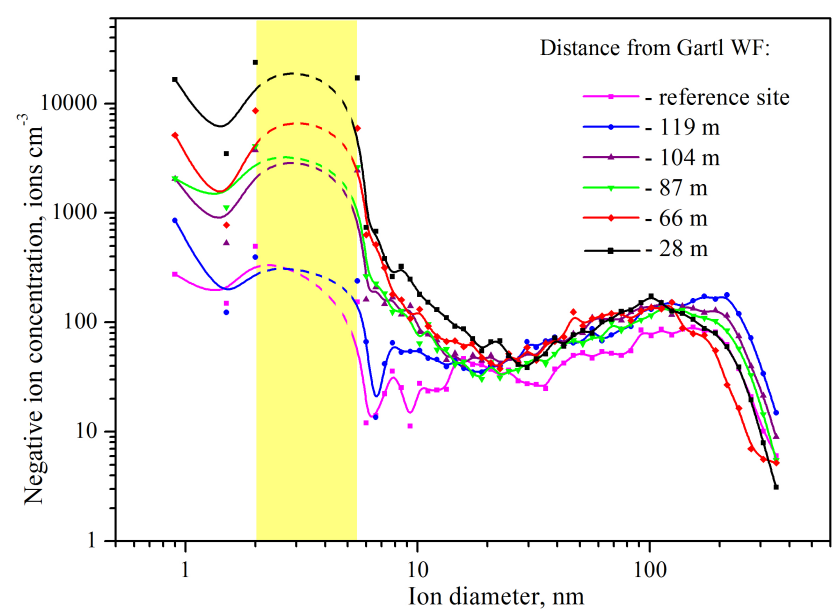

Fig. 13. Ion concentration distribution by size, measured at different distances on 3 July 2010 at Gartl WF, Döllach. Shaded area indicates interpolated values (cubic B-spline) between CDI-06 (0.36$2.0 \mathrm{~nm})$ and SMPS $(5.5-350 \mathrm{~nm})$ measurements. The reference site data series (magenta curve) represents the reference site where no WF-generated ions were expected to occur.

tained (Fig. 11), but with huge deviations in the overall concentration.

Figure 13 demonstrates the distribution of the negative ion concentration by their size. It reveals a similar size distribution as observed at the Krimml waterfall (compare with Fig. 9). This observation is interesting, because there is a clear difference in both, the topography as well as the height of the falls. The ion concentration-peak in the size range of $0.36-0.9 \mathrm{~nm}$ at the reference points of both WFs (Fig. 9 and 13) is a consequence of different source and formation mechanisms as outlined above. Due to orographical reasons (steep cliff), the last point approachable for the experimental measurements was $120 \mathrm{~m}$ away from the WF. The selected 
reference site was near the village of Döllach (Carinthia), a few kilometres from the falls on the opposite side of the valley.

\section{Conclusion}

In this study, spatial, time and size distributions of WFgenerated ions on several alpine WFs are presented. The size range of ions from 0.36 to $350 \mathrm{~nm}$ was measured at $2 \mathrm{WFs}$ in the Austrian Alps, using a Gerdian-type ion counter and a Scanning Mobility Particle Sizer, adapted for negative ion counting purposes.

Although the daily as well as seasonal variations of WFrelated water masses (maxima versus minima differ several times) is reflected in the fluctuating ion concentrations, concentration maxima of generated ions are more related to the geological structure of the WF than on the amount of water pouring down. Nonetheless, the combined mix of parameters such as topographic configuration (height and shape of the WFs and surrounding rock topography), quantity of water and local meteorological conditions are reflected in the detected ion concentrations of the fall. These parameters also determine the quantity of water aerosols dispersed in the air, which in turn, can increase the ion sink rate.

Spatial distribution of aerosolized ions of alpine WFs is attributed to air flow trajectories, which typically follow the course of the river bed. In the case of the Krimml waterfall, generated ions reached distances up to $500 \mathrm{~m}$ which implies maximal WF-related ion lifetime of approximately $120 \mathrm{~s}$. Compared with the measurements from the artificial WF, we can conclude that bubble break-up on aqueous surfaces along with splashing of water on solid surfaces are the major sources of WF-related ions.

The investigated WFs are embedded in very different topographical settings, yet their ion size distribution was found to be similar in shape thus confirming the data of Laakso et al. (2007). The abundance of negative small and intermediate ions generated by these WFs was found to be in the size range of $0.36-25 \mathrm{~nm}$, with a maximal concentration peak measured at the size window of $1.5-2 \mathrm{~nm}$, i.e. in the mobility range of $0.55-0.3 \mathrm{~cm}^{2} \mathrm{~V}^{-1} \mathrm{~s}^{-1}$. On the other hand, heavier sub-micrometer ions, in the range of 40 to $350 \mathrm{~nm}$, peaked in a size window at around $120 \mathrm{~nm}$. The generation of ions within the range from 0.9 to $1.5 \mathrm{~nm}$ was less dominant than those at 0.36 to 0.9 and 1.5 to $2.0 \mathrm{~nm}$, which is again in agreement with the results as reported by Laakso et al. (2007). Average negative ion concentrations have been found to be 11 to 80-times higher in the vicinity of the WFs, compared to the control sites. Positive ion generation by WFs could also be detected, but their concentration never exceeded triple fold, as compared to the control sites, and their spatial distribution, as well as their concentration differed greatly (Fig.6).
Acknowledgements. The study was funded by the "Salzburger Nationalparkfonds" with leader funds of the EU program for rural development. It was partially also supported by MES Serbia No: 171020, 45003.

Edited by: M. Kulmala

\section{References}

Aplin, K. L.: Composition and measurement of charged atmospheric clusters, Space Sci. Rev., 137, 213-224, 2008.

Aplin, K. L.: Aspirated Capacitor Measurements of Air Conductivity and Ion Spectra Rev. Sci Instrum., 76, 10450, 2005.

Blanchard, D. C.: Electrified droplets from the bursting of bubbles at an air-sea water interface, Nature, 175, 334-336, 1955.

Botti, A., Bruni, F., Imberti, S., Ricci, M. A., and Soper, A. K.: Solvation shell of $\mathrm{OH}^{-}$ions in water, J. Mol. Liq., 117, 81-84, 2004.

Chalmers, J. A.: Atmospheric Electricity, Pergamon Press, Oxford, London, UK, 1967.

Chandrashekara, M. S., Sannapp, J., and Paramesh, L.: Studies on atmospheric electrical conductivity related to ${ }^{222} \mathrm{Rn}$ and its progeny concentrations in the lower atmosphere at Mysore, Atmos. Environ., 40, 87-89, 2006.

Chapman, S.: Carrier mobility spectra of liquids electrified by bubbling, Phys. Rev., 54, 520-527, 1938a.

Chapman, S.: Interpretation of carrier mobility spectra of liquids electrified by bubbling and spraying, Phys. Rev., 54, 528-533, $1938 b$.

Flagan, R. C.: History of Electrical Aerosol Measurements, Aerosol Sci. Tech., 28, 301-380, 1998.

Gathman, S. G. and Hoppel, W. A.: Electrification processes over Lake Superior, J. Geophys. Res., 75, 1041-1048, 1970.

Gerdien, H.: Demonstration eines Apparates zur absoluten Messung der elektrischen Leitfahigheit der Luft, Phys. Zeitung, 6, 800-801, 1905.

Heim M., Kasper, G., Reischl, G., and Gerhart, C.: Performance of a new commerical electric mobility spectrometer, Aerosol Sci. Techn., 38, 3-14, 2004.

Hirsikko, A., Bergman, T., Laakso, L., Dal Maso, M., Riipinen, I., Hõrrak, U., and Kulmala, M.: Identification and classification of the formation of intermediate ions measured in boreal forest, Atmos. Chem. Phys., 7, 201-210, doi:10.5194/acp-7-201-2007, 2007.

Hirsikko, A., Nieminen, T., Gagné, S., Lehtipalo, K., Manninen, H. E., Ehn, M., Hõrrak, U., Kerminen, V.-M., Laakso, L., McMurry, P. H., Mirme, A., Mirme, S., Petäjä, T., Tammet, H., Vakkari, V., Vana, M., and Kulmala, M.: Atmospheric ions and nucleation: a review of observations, Atmos. Chem. Phys., 11, 767798, doi:10.5194/acp-11-767-2011, 2011.

Hoppel, W. A. and Frick, G. M.: Ion-aerosol attachment coefficients and the steady state charge distribution on aerosols in a bipolar ion environment, Aerosol Sci. Technol., 5, 1-21, 1986.

Hoppel, W. A., Anderson, R. V., and Willett, J. C.: in The Earth's Electrical Environment, National Academy Press, Washington, USA, 149-165, 1986.

Hõrrak, U.: Air ion mobility spectrum at a rural area. Dissertationes Geophysicales Universitat Tartuensis, Tartu, Estonia, 2001. 
Hõrrak, U., Iher, H., Luts, A., Salm, J., and Tammet, H.: Mobility spectrum of air ions at Tahkuse Observatory, J. Geophys. Res., 99, 10697-10700, 1994.

Hõrrak, U., Salm, J., and Tammet, H.: Statistical characterization of air ion mobility spectra at Tahkuse Observatory: Classification of air ions, J. Geophys. Res., 105, 9291-9302, 2000.

Hõrrak, U., Tammet, H., Aalto, P. P., Vana, M., Hirsikko, A., Laakso, L., and Kulmala, M.: Formation of charged nanometer aerosol particles associated with rainfall: atmospheric measurements and lab experiment. Report Series in Aerosol Science, 80, 180-185, 2006.

Hõrrak, U., Aalto, P. P., Salm, J., Komsaare, K., Tammet, H., Mäkelä, J. M., Laakso, L., and Kulmala, M.: Variation and balance of positive air ion concentrations in a boreal forest, Atmos. Chem. Phys., 8, 655-675, doi:10.5194/acp-8-655-2008, 2008.

Hulthe, G., Stenhagen, G., Wennerström, O., Ottosson, CH.: Water clusters studied by electrospray mass spectrometry, J. Chromatogr. A., 777, 155-165, 1997.

Iwama, H.: Negative air ions created by water shearing improve erythrocyte deformity and aerobic metabolism, Indoor Air, 14, 293-297, 2004.

Kolarž, P., Filipović, D., and Marinković, B.: Zeroing and testing units developed for Gerdien atmospheric ion detectors, Rev. Sci. Instrum., 76, 046107, 2005.

Kolarž, P., Filipović, D., and Marinković, B.: Daily variations of indoor air-ion and radon concentrations, Appl. Radiat. Isotopes, 67, 2062-2067, 2009.

Kolarž, P., Miljković, B., and Ćurguz, Z.: Air-ion counter and mobility spectrometer, Nucl. Instr. Meth. B, 279, 219-222, 2012.

Laakso, L., Petäjä, T., Lehtinen, K. E. J., Kulmala, M., Paatero, J., Hõrrak, U., Tammet, H., and Joutsensaari, J.: Ion production rate in a boreal forest based on ion, particle and radiation measurements, Atmos. Chem. Phys., 4, 1933-1943, doi:10.5194/acp-41933-2004, 2004.

Laakso, L., Hirsikko, A., Grönholm, T., Kulmala, M., Luts, A., and Parts, T.-E.: Waterfalls as sources of small charged aerosol particles, Atmos. Chem. Phys. Discuss., 6, 9297-9314, doi:10.5194/acpd-6-9297-2006, 2006.

Laakso, L., Hirsikko, A., Grönholm, T., Kulmala, M., Luts, A., and Parts, T-E.: WFs as sources of small charged aerosol particles, Atmos. Chem. Phys., 7, 2271-2275, doi:10.5194/acp-72271-2007, 2007.

Lenard, P.: Über die Elektrizität der Wasserfälle, Ann Phys (Leipz), 46, 584-636, 1892.
Lenard, P.: Über Wasserfallelektrizität und über die Oberflächenbeschaffenheit der Flüssigkeiten, Ann. Phys., 352, 463-524, 1915.

Levin, Z.: Charge separation by splashing of naturally falling raindrops, J. Atmos. Sci., 28, 543-548, 1971.

Luts, A., Parts, T., Laakso, L., Hirsikko, A., Grönholm, Tand Kulmala, M.: Some air electricity phenomena caused by WFs, Correlative study of the spectra, Atmos. Res., 91, 229-237, 2009.

Misaki, M.: Studies on the atmospheric ion spectrum I. (Procedures of experiments and data analysis), Pap. Met. Geophys., 12, 247260, 1961.

Parfenyuk, V. I.: Surface potential at the gas-aqueous solution interface, Colloid J., 64, 588-595, 2002.

Parts, T., Luts, A., Laakso, L., Hirsikko, A., Grönholm, T., and Kulmala, M.: Chemical composition of waterfall-induced air ions, spectrometry vs. simulations, Boreal. Environ. Res., 12, 409420, 2007.

Reiter, R.: Charges on particles of different size from bubbles of Mediterranean Sea surf and from waterfalls, J. Geophys. Res., 99, 10807-10812, 1994.

Takahashi, K., Otsuki, T., Mase, A., Kawado, T., Kotani, M., Ami, K., Matsushima, H., Nishimura, Y., Miura, Y., Murakami, S., Maeda, M., Hayashi, H., Kumagai, N., Shirahama, T., Yoshimatsu, M., and Morimoto, K.: Negatively-charged air conditions and responses of the human psycho-neuro-endocrino-immune network, Environ. Int., 34, 765-772, 2008.

Tammet, H.: The aspiration method for the determination of atmosphericion-spectra, Israel Program for Scientific Translations, Jerusalem, 1970.

Tammet, H.: Size and mobility of atmospheric particles, clusters and ions, J. Aerosol. Sci., 26, 459-475, 1995.

Tammet, H., Hõrrak, U., and Kulmala, M.: Negatively charged nanoparticles produced by splashing of water, Atmos. Chem. Phys., 9, 357-367, doi:10.5194/acp-9-357-2009, 2009.

Yamada, R., Yanoma, S., Akaike, M., Tsuburaya, A., Sugimasa, Y., Takemiya, S., Motohashi, H., Rino, Y., Takanashi, Y., and Imada, T.: Water-generated negative air ions activate NK cell and inhibit carcinogenesis in mice, Cancer Letters, 239, 190-197, 2005.

Vostrikov, A. A., Drozdov, S. V., Rudnev, V. S., and Kurkina, L. I.: Molecular dynamics study of neutral and charged water clusters, Comput. Mater. Sci., 35, 254-260, 2006.

Zilch, L., Maze, J., Smith, J., Ewing, G., and Jarrold, M.: Charge separation in the aerodynamic breakup of micrometer-sized water droplets, J. Phys. Chem. A., 112, 13352-13363, 2008. 